\title{
Histological Assessment of the Effect of Lacosamide on the Kidney Tissue of Pregnant Albino Rats
}

\author{
Ahmed s Ashour ${ }^{1 *}$ and Tanya PA Kirpalani ${ }^{2}$ \\ ${ }^{1}$ Assistant Professor in Biomedical Dental Sciences, Imam Abdulrahman Bin Faisal University, Kingdome of Saudi Arabia \\ ${ }^{2}$ Physician Assistant, Nihon University School of Medicine, Japan
}

*Corresponding author: Ahmed s Ashour, Assistant Professor in Biomedical Dental Sciences, Imam Abdulrahman Bin Faisal

University, Kingdome of Saudi Arabia

\begin{tabular}{l}
\hline ARTICLE INFO \\
\hline Received: 幽 January 22, 2020 \\
Published: 幽 January 29, 2020 \\
\hline Citation: Ahmed s Ashour, Tanya PA \\
Kirpalani. Histological Assessment of the \\
Effect of Lacosamide on the Kidney Tissue \\
of Pregnant Albino Rats. Biomed J Sci \& Tech \\
Res 25(1)-2020. BJSTR. MS.ID.004151.
\end{tabular}

Keywords: Lacosamide; Seizure; Kidney; Pregnant Rats

Abbreviations: AED: Antiepileptic Drugs; PCT: Proximal Convoluted Tubules; DCT: Distal Convoluted Tubules; DRESS: Drug Reaction with Eosinophilia and Systemic Symptoms; CRRT: Continuous Renal Replacement Therapy; RRT: Renal Replacement Therapy

\section{ABSTRACT}

Objective: Lacosamide is an antiseizure agent and most commonly prescribed drugs for epilepsy. The aim of this work was evaluating the effect of Lacosamide (at its therapeutic range) on the kidney of pregnant albino rats.

Methods: Forty pregnant rats were divided into two groups, group I received 1.5 $\mathrm{ml} /$ day distilled water in two divided doses throughout pregnancy. Rats in the group II received $1.5 \mathrm{ml} /$ day distilled water (containing $36 \mathrm{mg}$ Lacosamide) two divided doses. At the end of the experiment, blood samples were collected, and the sera were separated and used for biochemical analysis. The Kidneys were excised and examined by light and electron microscopic.

Results: Treatment with Lacosamide induced undesirable histopathological changes in the kidney. These changes were in the form of fusion and effacement of secondary foot processes, thickening and disruption of the glomerular basement membrane, widening of the Bowman's spaces, cytoplasmic vacuolation, and swollen mitochondria with loss of their cristae. Such changes were confirmed by alteration of some biochemical parameters of kidney functions.

Significance: Authors concluded that Lacosamide induced adverse effects on the kidney of pregnant albino rats. Further investigations are needed to identify the mechanism of Lacosamide toxicity.

\section{Introduction}

Epilepsy is a common disorder affecting approximately more than 1.000 .000 women in fertile period [1]. The prevalence of epilepsy was estimated to be $0.4 \%$ in pregnant women [2]. Pregnant women with epilepsy are advised to maintain Antiepileptic Drugs (AED) [3]. Pharmacological treatment options of epilepsy comprise conventional AED (valproate) and second-generation agents (Lacosamide) [4]. Some undesired effects associated with conventional AED, such as Stevens-Johnson syndrome and memory deterioration [5]. The effectiveness of the second generation drugs, seems to be similar to that of the conventional AED. However, the second-generation drugs, offer a lower risk of interactions with other medications, simpler titration and improved tolerability [4]. Lacosamide was developed as an analogue of piracetam, a drug used to improve cognitive function [6]. it is recognized for adjunct therapy of focal onset in children and adults [7].

Peak plasma concentrations of the drug in 1.3 hours. Twothirds of the drug is excreted in the urine [8]. Studies reported adverse effects associated with Lacosamide therapy e.g. vomiting, irritability, headaches, inflammation of the nose and throat, and sleepiness [9]. Data on the adverse effects of Lacosamide during pregnancy is still limited [10]. So, this work aimed to assess the effect of Lacosamide on kidney of pregnant albino rats. 


\section{Materials and Methods}

Lacosamide was available in the form of tablets $500 \mathrm{mg}$ each. The chosen dose for adult humans was $2000 \mathrm{mg} /$ day. The equivalent dose for adult rat weighting about $200 \mathrm{gm}$ is $36 \mathrm{mg} /$ day [11].

The forty pregnant rats were divided equally into two groups:

a) Group I (control): received $1.5 \mathrm{ml} /$ day distilled water in two divided doses throughout pregnancy.

b) Group II (treated): received $1.5 \mathrm{ml} /$ day distilled water (containing $36 \mathrm{mg}$ Lacosamide) in two divided doses throughout pregnancy.

At the end of the experiment,

1. Blood samples were collected [12]. The sera were separated then preserved at $-20^{\circ} \mathrm{C}$ for biochemical analysis. Creatinine level in $\mathrm{mg} / \mathrm{dl}$ was determined [13]. Blood urea nitrogen measurement in $\mathrm{mg} / \mathrm{dl}$ [14].

2. Rats were sacrificed then kidneys were excised and used for:

A. Lght microscopy Sections were stained with

I. Hematoxylin and Eosin to study the general histological features of selected kidney tissue.

II. Immunohistochemistry, anti-bovine type IV (collagen rabbit serum was used as first antibody, and biotinylated antirabbit Iggy goat serum was used as secondary antibody)

B. Electron microscopic examination.

\section{Results}

\section{Histopathological Results}

a) Light microscopy(H\&E): Group I (control group): showed Malpighian corpuscles (formed of glomerulus surrounded by Bowman's capsule) and tubules (Proximal Convoluted Tubules (PCT), Distal Convoluted Tubules (DCT) and collecting tubules). The PCT and DCT were lined by cuboidal cells, however, the DCT exhibited a greater number of lining cells, and wide Lumina with no brush border (Figure 1a). Group II: some shrunken glomeruli with wide capsular spaces. Some of the glomerular tuft nuclei were irregular and deeply stained. Some of the epithelial cells lining the renal tubules showed cytoplasmic vacuolization, intraluminal exfoliation as well as small darkly stained irregular nuclei. The brush border of the some PCT became disrupted (Figure 1b).
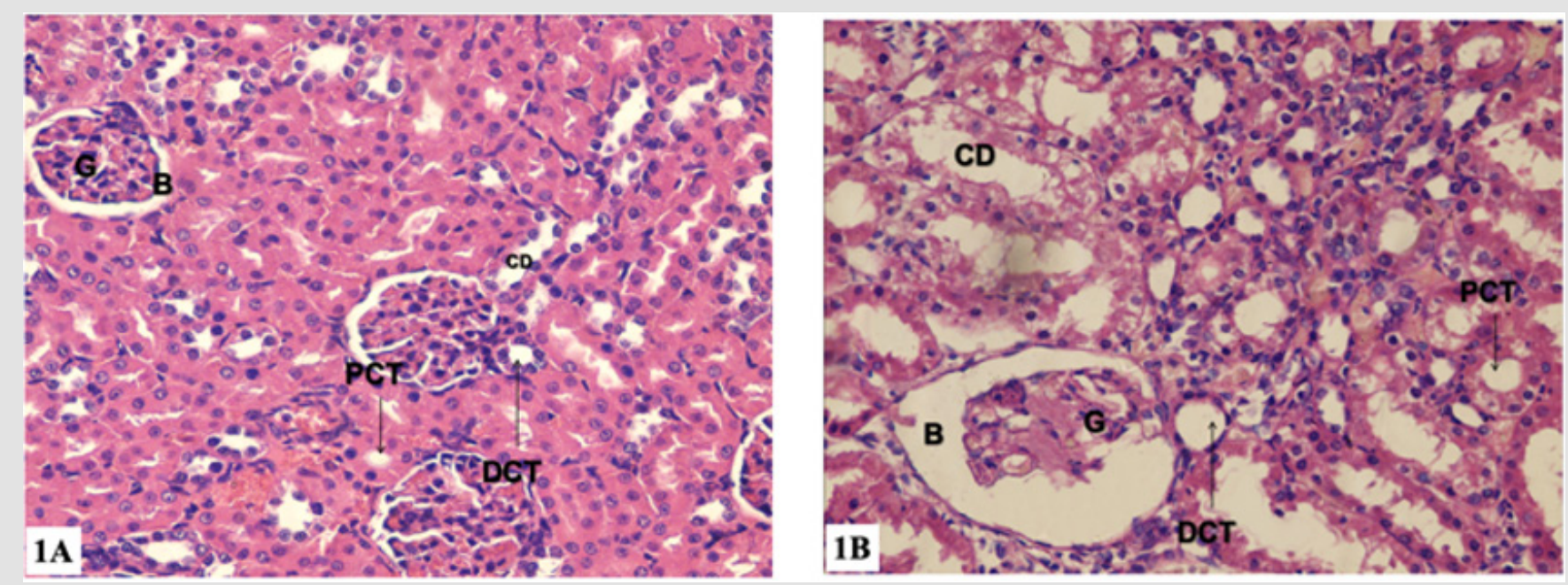

Figure 1: Photomicrographs of renal cortex transverse sections (H\&E $\times 400$ magnification).

a) 1a: group I: showing normal histological structure of renal cortex with many rounded renal corpuscles formed of two parts, first, the Glomerulus(G) which is formed of a coiled mass of capillaries. Second, the Bowman's capsule (B). Renal corpuscles are surrounded with Proximal Convoluted Tubule (PCT), distal convoluted Tubule (DCT) and Collecting Duct (CD).

b) 1b: group II: showing rounded renal corpuscles formed of a shrunken glomerulus (G) surrounded with Bowman's Capsule (B). Proximal Convoluted Tubule (PCT), Distal Convoluted Tubule (DCT) and Collecting Duct (CD) are seen with vacuolated cytoplasm. The Lumina of some renal tubules contain cellular exfoliation.

b) Light microscopy(immunohistochemistry): Group

I (control group): no brownish coloration in the mesangial matrix indicating negative reaction for collagen IV (Figure 2a). Group II: strong positive reaction for collagen IV (Figure 2b). 

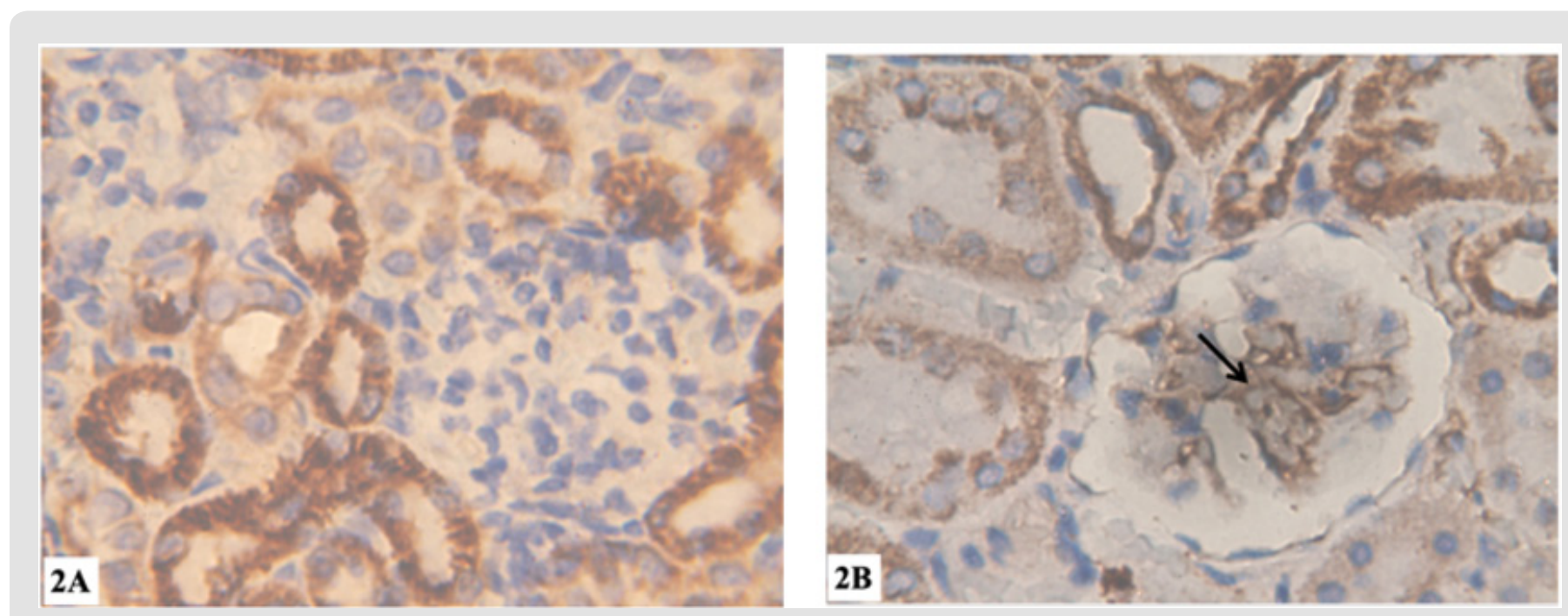

Figure 2: Photomicrographs of renal cortex transverse sections (Collagen IV immunostaining X1000).

a) 2a: group I: showing no brownish coloration in the mesangial matrix indicating negative reaction for collagen IV.

b) 2b: group II: showing strong positive reaction for collagen IV (arrow).

\section{Electron Microscopy:}

a) Group I (control group): showed renal corpuscles formed tuft of capillaries lined with fenestrated endothelium and wrapped by podocytes (had large irregular euchromatic nuclei, primary processes and secondary processes with Filtration slits). The glomerular basement membrane appeared with its trilaminar structure. The epithelial cells lining the PCT showed many mitochondria lodged between the basal infoldings and a noticeable number of mitochondria of different sizes and shapes were situated on the upper portion of the cells. In addition to mitochondria, endoplasmic reticulum, ribosomes, Golgi complex and lysosomes appeared clearly. At apex of the epithelial cells, tall and closely packed projections called microvilli appeared clearly. The nuclei of these epithelial cells were large, euchromatic with well demarcated nuclear membrane. The nuclei contained clumps of heterochromatin and nucleoli. The epithelial cells lining the DCT were resting on a regular basement membrane that exhibited basal infoldings ran perpendicular to it (Figures 3a \& 3b).

b) Group II: showed many histopathological changes. Thickening of the glomerular basement membrane and loss of its trilaminar structure, some of the secondary foot processes were effaced or fused the epithelial cells lining some PCT had small nuclei with irregular ill demarcated nuclear envelope. Loss of cristae or swollen of their mitochondria were longitudinally arranged with. The epithelial cells lining some DCT showed small nuclei with increased heterochromatin. Their cytoplasm exhibited rarefaction, loss of basal infoldings, disorganized mitochondria with loss of their cristae (Figures 3c \& 3d).

Biochemical Results: Statistical analysis of the mean levels of Urea and creatinine in groups I and II revealed significant increase in group II as compared with group I $(\mathrm{P}<0.05)$ (Table 1$)$.

Table 1: Means and standard deviations of Urea and creatinine of pregnant rats in groups' I - II.

\begin{tabular}{|c|c|c|c|c|}
\hline \multicolumn{2}{|c|}{ Measurements } & \multicolumn{2}{c|}{ Pregnant rats at one day after delivery } & \multicolumn{2}{c|}{ T test } \\
\cline { 2 - 5 } & Group I (n=20) & Group II (n = 20) & t \\
\hline Urea $(\mathrm{mg} / \mathrm{dl})$ & Mean \pm SD Range & $37.39 \pm 1.06619436-39$ & $49.65 \pm 1.48032847-51$ & 2.119915 \\
\hline Creatinine $(\mathrm{mg} / \mathrm{dl})$ & Mean \pm SD Range & $0.663 \pm 0.0212080 .64-0.69$ & $0.781 \pm 0.0088560 .78-0.8$ & 2.178913 \\
\hline
\end{tabular}



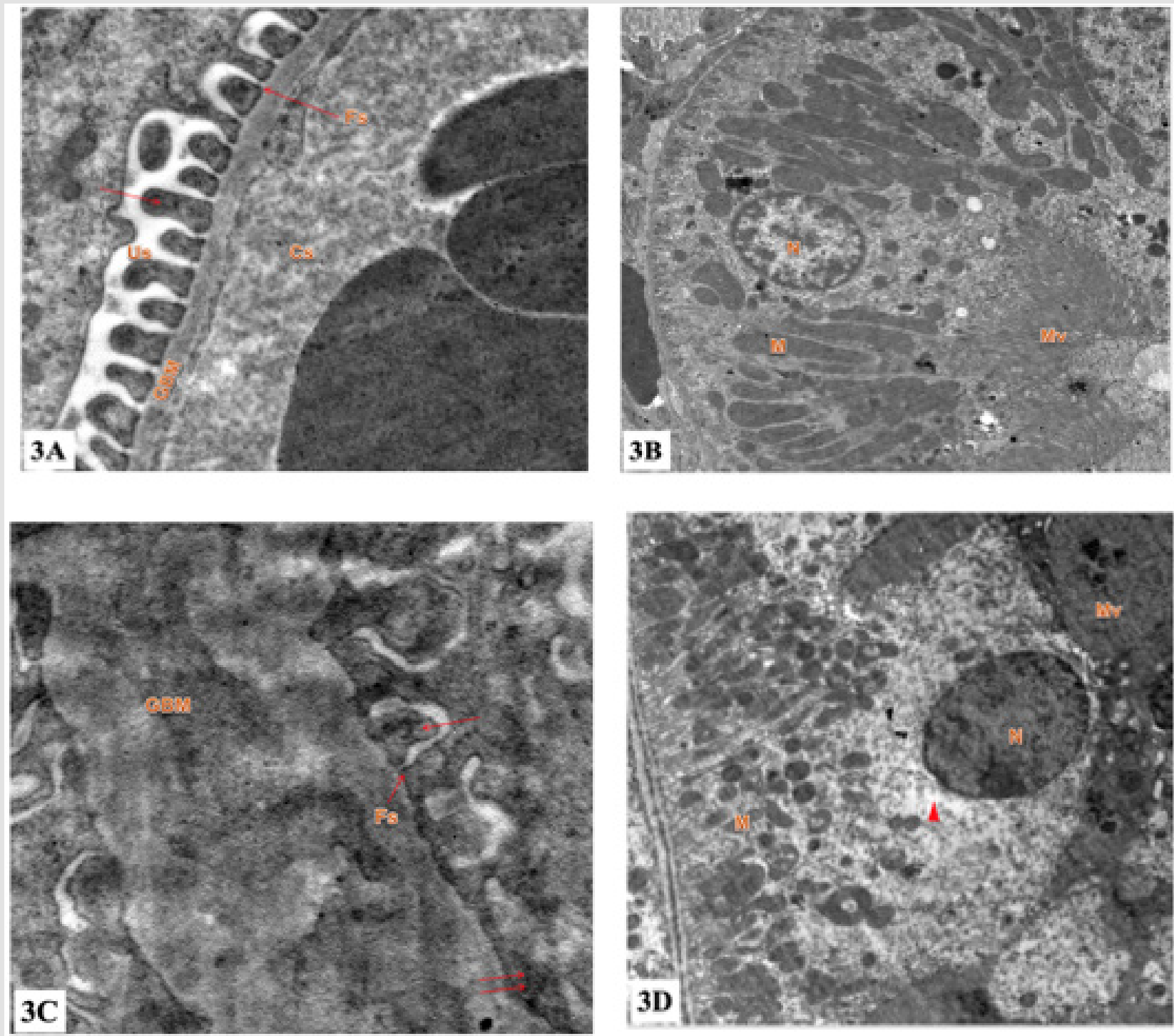

Figure 3: Electron micrograph of the ultrathin renal cortex section (TEM $\times 10,000$ magnification).

a) 3a: group I: showing Glomerular Basement Membrane (GBM) formed of a central lamina densa and lamina rara on either side, separating between Capillary Space (Cs) and Urinary Space (Us). Foot processes of podocytes (arrow) are separated from one another by a regular narrow space called Filtration Slit (Fs).

b) 3b: group I: showing the lining epithelium of proximal convoluted tubules. The Nucleus $(\mathrm{N})$ is rounded, regular contour and euchromatic. Mitochondria (M) are basally oriented and lie within basal infoldings. Apical surface has numerous Microvilli $(\mathrm{Mv})$ forming the brush border.

c) 3c: group II: showing thick Glomerular Basement Membrane (GBM) which separates between Capillary Space (Cs) and Urinary Space (Us). Foot processes of podocytes (arrow) are separated from one another by a regular narrow space called Filtration Slit (Fs). Effacement of foot processes is obvious (double arrow).

d) 3d: group II: showing lining epithelium of proximal convoluted tubules. Nucleus $(\mathrm{N})$ is rounded. The basal cytoplasm is rich in Mitochondria (M) which show pleomorphism. Apical surface has numerous microvilli (Mv). Cytoplasmic vacuolation are seen (arrowhead).

\section{Discussion}

The current research revealed that administration of Lacosamide to pregnant albino rats induced degenerative changes in their kidney tissue. The changes were in the form of thickening and disruption of the glomerular basement membrane, fusion and effacement of secondary foot processes, pyknosis of some of the glomerular tuft nuclei and widening of the Bowman's spaces. Lacosamide treatment also led to disorganized mitochondria in the cells lining the renal tubules, cytoplasmic vacuolization and intraluminal exfoliation. In addition, Lacosamide treatment led 
to an increased heterochromatin contents of some nuclei of the cells lining the renal tubules, such pathological changes were confirmed by parallel significant elevation of the levels of urea and creatinine. These findings were in line with Leblanc and Plaisance who reported occurrence of acute kidney injury and potentially lifethreatening nature of Drug Reaction with Eosinophilia and Systemic Symptoms (DRESS) two months after starting Lacosamide to a 75-year-old man with glioblastoma, With leukocytosis, eosinophilia and thrombocytopenia [15].

Also, the results of the present study were in line with some researchers who also reported occurrence of kidney injury after the initiation of Lacosamide treatment for new-onset seizures in a 23-year-old fertile female patient. Based on the time course of the patient's elevation in the level of serum creatinine and the exclusion of other causes, the authors suggested that Lacosamide treatment was contributed to the acute kidney injury [16]. On the other hand, the results of the current study were antithesis to other researchers who didn't detect major side effects any patients after use of intravenous Lacosamide in patients with renal impairment [17]. The results of the present study also were contrary to another study, the authors presented two pediatric cases of Lacosamide overdose for one month and didn't observe severe side effects in the patients. So, they suggested that accidental treatment with an overdose of Lacosamide in children for long period was not accompanied with serious side effects [18].

In the current study, the degenerative changes that were observed in the and kidney might be due to disturbance in the oxidant/antioxidant ratio. Such suggestion was supported by researchers [19-23] who explained that genotoxic potential of Lacosamide by decreased free radical neutralization and/or an increased production of free radicals.Other researcher reported that, relationship between serum lacosamide concentrations and clinical efficacy is not well understood; thus, therapeutic drug monitoring is not routinely recommended [24-27]. Yet, we demonstrated that measuring serum lacosamide concentrations in the critically ill population during continuous renal replacement therapy may be useful to individualize dosing programs [28-34]. Further pharmacokinetic studies of lacosamide may be necessary to generate widespread dosing recommendations [5]. Mahmoud SH reported that Continuous Renal Replacement Therapy (CRRT) is used for managing acute kidney injury in critically ill patients [35-37]. Removal of Antiepileptic Drugs (AEDs) by CRRT could be significant and may complicate patients' intensive care unit stay [11]. Other researcher reported that additional studies are necessary before specific dosing recommendations can be made for Lacosamide in critically ill patients receiving Renal Replacement Therapy (RRT) after evaluating current literature for dosing recommendations for the use of antiepileptic medications in patients receiving RRT [2].

\section{Conclusion}

Authors concluded that Lacosamide induced dangerous effects on the kidney of pregnant albino rats. Continuous assessment of the kidney functions during Lacosamide therapy is advised. In addition, further investigations are recommended to clarify the mechanism of Lacosamide toxicity [38].

Declaration of Conflicts of Interest: No conflicts of interest.

\section{Funding Details}

This research did not receive any specific grant from funding agencies in the public, commercial, or not-for-profit sectors.

\section{References}

1. Hayat MA (2000) Principles and techniques of electron microscopy: Biological applications. ( $4^{\text {th }}$ edn.), Cambridge University Press. USA, PP. 4-85.

2. Xiong N, Hou L, Lu N, Mohamed AA, Wang T, et al. (2012) Probable Lacosamide-related serum alkaline phosphatase elevation. BMC Neurology 12: 97.

3. Rang HP, Ritter JM, Flower RJ, Henderson G (2016) Rang and Dale's Pharmacology. ( $8^{\text {th }}$ edn), Pbl. Elsevier Ltd. pp. 559-569.

4. Omer HAM, Kutb MA (2015) Chronic histopathological effects of Lacosamide on some internal organs of adult albino rats. Egyptian Journal of Forensic Sciences 5: 41-45.

5. Mahmoud SH (2017) Antiepileptic Drug Removal by Continuous Renal Replacement Therapy: A Review of the Literature. Clin Drug Investig 37(1): 7-23.

6. Rogawski MA, Bazil CW (2008) New molecular targets for antiepileptic drugs: 2, SV2A and Kv7/KCNQ/M potassium channels. Curr Neurol Neurosci Rep 8(4): 345-352.

7. Sharma U, Pal D, Prasad R (2014) Alkaline phosphatase: An overview. Indian J Clin Biochem 29(3): 269-278.

8. Spengler DC, Montouris GD, Hohler AD (2014) Levetiracetam as a Possible Contributor to Acute Kidney Injury. Clinical Therapeutics 36(8): 1303-1306.

9. Sethi NK, Sethi PK, Torgovnick J (2013) Asymptomatic elevation of enzymes due to Lacosamide: A case report. Drug Metabol Drug Interact 28(2): $123-124$

10. Bansal R, Suri V, Chopra S, Aggarwal N, Sikka P, et al. (2008) Levetiracetam use during pregnancy in women with epilepsy: Preliminary observations from a tertiary care center in Northern India. Indian J Pharmacol 50(1): 39-43.

11. Patel SI, Pennell PB (2016) Management of epilepsy during pregnancy: An update. Ther Adv Neurol Disord 9(2): 118-129.

12. Franquiz MJ, Kalaria SN, Armahizer MJ, Gopalakrishnan M, McCarthy PJ, et al. (2018) Lacosamide Pharmacokinetics in a Criticallylll Patient During Continuous Renal Replacement Therapy. pharma practice 41: 718-726.

13. Harden CL, Meador KJ, Pennell PB, Hauser WA, Gronseth GS, et al. (2009) Practice parameter update: Management issues for women with epilepsy-focus on pregnancy (an evidence-based review): Teratogenesis and perinatal outcomes: report of the Quality Standards Subcommittee and Therapeutics and Technology Assessment Subcommittee of the American Academy of Neurology and American Epilepsy Society. Neurology 73(2): 133-141.

14. Paget GC, Barens JM (1964) Toxicity in evaluation of drug activities. pharmaceutic. ed., Lournace and Bacharachai, Academic press, London and New York. pp. 1-13. 
15. Neves EG, Ramos-Perez FM, Freitas DQ, Bóscolo FN, Almeida SM (2013) Radioprotective effect of sodium selenite on developing teeth. Brazilian Dental Journal 24(4): 375-379.

16. Thomas L (1998) Alanine aminotransf-erase (ALT), aspartate aminotrasferase (AST), in Thomas, L. editor. Clinical Lab-oratory Diagnostics. Frankfurt: TH-Books Verlagsgesellschaft, ( $1^{\text {st }}$ edn.), pp. 5556.

17. Lyseng-Williamson KA, Lacosamide (2011) A Review of its use in epilepsy. Drugs 71(4): 489- 514

18. Pipkin BF (1984) Medical Statistics made easy ( $5^{\text {th }}$ edn.), Churchill living stone, New York: 46-56.

19. Fossati P, Prencipe L, Berti G (1983) Enzymic creatinine assay: A new colorimetric method based on hydrogen peroxide measurement. Clin Chem 29: 1494-1496.

20. Attilakos A, Dinopoulos A, Paschalidou M (2018) Effect of Lacosamide Monotherapy on Enzymes and Creatine Kinase Concentrations in Children with Epilepsy: A Prospective Study. Journal of clinical neurology (Seoul, Korea) 14(4): 594-595.

21. Bancroft JD, Gamble M (2008) Theory and practice of histologica techniques. ( $6^{\text {th }}$ edn.), Pbl. Churchill Livingston, Edinburg, pp. 340-348.

22. Broli M, Provini F, Naldi I, Bisulli F, Sama C, et al. (2010) Unexpected gamma glutamyltransferase rise increase during Lacosamide monotherapy. Epileptic Disord 12(1): 81-82

23. Ding SP, Li JC, Jin C (2003) A mouse model of severe acute pancreatitis induced with caerulein and lipopolysaccharide. World J Gastroenterol 9(3): 584-589.

24. EL-Shorbagy HM, Hamdi H (2016) Genotoxic and mutagenic studies of the antiepileptic drug Lacosamidee in pregnant rats and their fetuses. Int J Pharm Sci 8(2): 82-88.

25. Kim J, Seok, YM, Jung KJ, Park KM (2009) Reactive oxygen species/ oxidative stress contributes to progression of kidney fibrosis following transient ischemic injury in mice. Am J Physiol Renal Physiol 297(2): F461-F470.

26. Lapmag A, Lertsinudom S, Chaiyakam A, Sawanyawisuth k, Tiamkao $S$ (2018) Clinical outcomes of intravenous Lacosamide treatment in patients with renal impairment. Neurology International 10(3): 7469.

\section{ISSN: 2574-1241}

DOI: $10.26717 /$ BJSTR.2020.25.004151

Ahmed s Ashour. Biomed J Sci \& Tech Res

(C) This work is licensed under Creative Commons Attribution 4.0 License

Submission Link: https://biomedres.us/submit-manuscript.php
27. Leblanc M, Plaisance M (2014) Lacosamide-Associated Acute Kidney Injury and Drug Reaction with Eosinophilia and Systemic Symptoms (DRESS) Syndrome. Open Journal of Nephrology 4: 152-155.

28. Orsonneau JL, Massoubre C, Cabanes M, Lustenberger P (1992) Simple and sensitive determination of urea in serum and urine. Clin Chem 38(5): 619-623.

29. Öztürk Z, Havalı C, Serdaroğlu A (2016) Two Cases of Lacosamide Overdose without Any Serious Side Effects Article in Gazi. Medical Journal 28(2):137-138.

30. Porter J, Rogawski MA (2012) Antiseizure Drugs In: Katzung, BG; Masters SB and Trevor AJ Basic and Clincal Pharmacology. (12 ${ }^{\text {th }}$ ed.), McGraw-Hill Companies pp. 409-424.

31. Rey JA (2015) Antipsychotic Drugs. In: Whalen K; Finkel R; Panavelil TA. Lippincott Illustrated Reviews: Pharmacology. ( $6^{\text {th }}$ ed.), Pbl. Wolters Kluwer pp: 147-157.

32. Shimizu I, Shimamoto N, Saiki K, Furujo M, Osawa K (2012) Lipid Peroxidation in Hepatic Fibrosis. In: Catala, A. Lipid Peroxidation. $\left(1^{\text {st }}\right.$ edn.), Intechopen pp. 483-492.

33. Syed AA, Adams CD (2012) Acute failure following Lacosamide therapy for seizure prophylaxis in traumatic brain injury. Case Reports in Clinical Medicine 1(2): 41-44.

34. Tomson T, Battino D (2009) Teratogenic effects of antiepileptic medications. Neurol Clin 27(4): 993-1002.

35. Vidaurre J, Gedela, S, Yarosz, S (2017) Antiepileptic Drugs and Disease. Pediatric Neurology 77: 23-36.

36. Yang H, Lauv S, Sinclair DA (2006) Nampt/PBEF/Visfatin: A regulator of mammalian health and longevity. Exper Geront 41(8): 718-726.

37.Zhu F, Lang SY, Wang XQ Shi XB, Ma YF, et al. (2015) Long-term effectiveness of antiepileptic drug monotherapy in partial epileptic patients: A 7-year study in an epilepsy center in China. Chin Med J 128(22): 3015-3022.

38. Smetana KS, Cook AM, Bastin ML, Oyler DR (2016) Antiepileptic dosing for critically ill adult patients receiving renal replacement therapy. J Crit Care 36: 116-124.

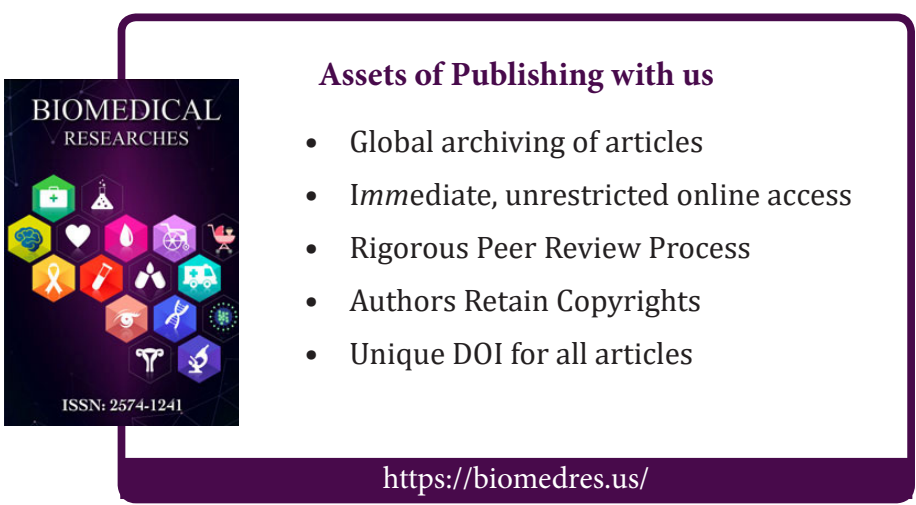

